\title{
CRITÉRIOS BIBLIOGRÁFICOS PARA ATRIBUIÇÃO DE TEXTOS A MACHADO DE ASSIS: ANÁLISE DO ENSAIO "A IMPRENSA NA ATUALIDADE" (1860)
}

\section{ALEX LARA MARTINS}

Instituto Federal do Norte de Minas Gerais

Almenara, Minas Gerais, Brasil

Resumo: Discutem-se as condições editoriais e os critérios de seleção para atribuição de autoria a peças de Machado de Assis. Ao mesmo tempo, apresentamse razões para se atribuir a Machado de Assis a autoria do ensaio "A imprensa na atualidade", publicado no Diário do Rio de Janeiro, em 27 de março de 1860. As razões são de ordem biográfica, estilística e comparativa. A crer nas justificativas apresentadas como critérios editoriais de seleção, esta seria a primeira contribuição de Machado para o Diário. O autor recupera e desenvolve teses de alguns artigos publicados anteriormente, sobretudo "O jornal e o livro" e "A reforma pelo jornal".

Palavras-chave: Machado de Assis; bibliografia; ensaio; imprensa.

\section{BIBLIOGRAPHICAL CRITERIA FOR ATTRIBUTING TEXTS TO MACHADO DE ASSIS: AN ANALYSIS OF THE ESSAY “A IMPRENSA NA ATUALIDADE” (1860)}

Abstract: The aim of this article is to indicate the editorial conditions and selection criteria for attributing authorship to works by Machado de Assis. At the same time, reasons are given for attributing the authorship of "A imprensa na atualidade" ["The Press Today"], published in the Diário do Rio de Janeiro, on March 27, 1860, to Machado. The reasons are biographical, stylistic and comparative. If the justifications for the editing criteria are correct, this would be Machado's very first contribution to the journal. The author returns to and develops theories in his earlier published articles, especially "O jornal e o livro" ["The Journal and the Book"] and "A reforma pelo jornal" ["The Reformation by the Journal"].

Keywords: Machado de Assis; Bibliography; Essay; Press. 


\section{Introdução}

crítica literária e a historiografia brasileira ganharam fôlego com a
digitalização de parte do acervo da Fundação Biblioteca Nacional,
cujos documentos são acessados diariamente dezenas de milhares de vezes. Em relação a Machado de Assis, o auxílio dessa ferramenta virtual deverá provocar o acréscimo significativo em sua produção bibliográfica conhecida e novas interpretações da obra. Sinais desses novos tempos são as páginas inéditas recolhidas no número 18 da revista Machado de Assis em Linha: uma colaboração de Machado no jornal ítalo-brasileiro Il Cosmopolita e uma crítica literária publicada no Jornal do Commercio. Revistas como a Machadiana Eletrônica e pesquisadores como Felipe Pereira Rissato e Wilton José Marques têm colaborado para a recuperação fidedigna das fontes e da obra de nosso escritor. Em alguns casos, não é necessário ser um machadiano devoto para se verificar a correção de um ou outro termo transcrito equivocadamente, nem mesmo para se encontrar alguma relíquia nos periódicos do oitocentos.

Com um pouco de persistência e algum senso de comparação, é possível identificar a pena de Machado, por exemplo, entre a contribuição de diversos escritores escondidos sob o pseudônimo coletivo Dr. Semana, que assina a série "Badaladas" no semanário humorístico Semana Ilustrada. Reconheça-se o esforço recente da pesquisadora Silvia Maria Azevedo para argumentar que a totalidade da série de crônicas pertence a Machado de Assis. Do mesmo modo, o mínimo de conhecimento biográfico deve proporcionar bom garimpo, nas páginas do Diário do Rio de Janeiro, entre março de 1860 e outubro de 1861, quando Machado trabalhou escrevendo críticas teatrais, cuidando da revisão - possivelmente, de anúncios -, até assumir, como cronista, uma coluna semanal para a cobertura de assuntos senatoriais.

O bibliógrafo Jean-Michel Massa se ressente de não ter desembaraçado do Diário do Rio de Janeiro as crônicas que poderiam ser atribuídas a Machado de Assis, indicando que um estudo sistemático deveria ser levado a cabo por outro pesquisador (MASSA, 1971, p. 282). A promessa é de bom garimpo virtual, porque muitas peças literárias escritas nesse periódico não estão assinadas e, por precaução ou falta de perícia, não foram recolhidas pelos bibliógrafos. Portanto, algumas páginas desse jornal podem compor parte das Obras completas ignoradas pela bibliografia machadiana, e 
sobretudo pelas seguidas edições de suas Obras completas, ainda assentadas sobre o estudo cinquentenário de J. Galante de Sousa.

Para o bibliógrafo, a utilização de um ou mais critérios de seleção não o redime de equívocos. Como já apontava Galante de Sousa: "praticar uma seleção é arcar com responsabilidade desnecessária e cometer um furto. Sonegar uma peça ao estudioso é fazê-lo correr o risco de chegar a conclusões erradas" (SOUSA, 1955, p. 8). Dada a relevância da obra de Machado de Assis, o trabalho do bibliógrafo e do editor ganham ainda mais importância. De modo geral, existem três critérios de seleção para atribuição de autoria a peças de Machado de Assis. O primeiro critério justifica-se por elementos extratextuais para a atribuição. A identificação de um pseudônimo ou de um elemento biográfico relevante, algumas vezes, é suficiente para imputar a Machado um conjunto de textos. Neste caso, quanto mais próxima de sua vida, maior é a credibilidade da fonte de atribuição: Max Fleiuss e Joaquim Serra descortinaram alguns pseudônimos utilizados por Machado, e Lúcia Miguel Pereira entrevistou alguns de seus contemporâneos para compor a sua biografia. O segundo critério está relacionado à análise vocabular e estilística dos textos supostos em comparação a textos originais escritos na mesma época. Trata-se de encontrar um modo machadiano de escrita. Novas ferramentas digitais de mineração de texto podem auxiliar os pesquisadores a extrair conceitos reiterativos e suas interligações. O terceiro critério apela ao conteúdo de outros textos originais escritos na mesma época ou em épocas distintas, quando se quer apontar alguma ruptura de pensamento e linguagem. Supõese que um autor como Machado de Assis possuía teses literárias próprias, em determinada época, e as modificava de maneira mais ou menos consistente, por exemplo, de um ecletismo na primeira juventude até certo ceticismo moral na maturidade.

\section{"A imprensa na atualidade": um ensaio encontrado de Machado de Assis?}

Os critérios gerais para atribuição de autoria apresentam especificidades e podem se interpor e se relacionar. Utilizando desses instrumentos de justificação, mapeia-se, nesta seção, as coordenadas de um tesouro que pode se comprovar ser de Machado: na primeira página da edição do dia 27 de março de 1860, lê-se o ensaio "A imprensa na atualidade", um resumo escolar, com avanços significativos, das mesmas teses defendidas por Machado, entre outros, em "O jornal e o livro" (Correio Mercantil, 10 e 12 jan. 
1859) e "A reforma pelo jornal" ( $O$ Espelho, 23 out. 1859). Essa coincidência temática oferece apenas um indício inicial e não definitivo. Em linha temporal, os bibliógrafos supõem que a primeira contribuição de Machado para o Diário tenha ocorrido dois dias depois da publicação daquele ensaio. Entre o editorial e o noticiário, na metade superior do jornal, o artigo "A imprensa na atualidade" abrange pouco mais de duas das sete colunas do espaço. Àquele indício inicial somam-se três critérios ou razões com as quais se costuma justificar a atribuição de textos a esse autor.

A primeira razão tem a ver com o lugar de Machado na redação do Diário do Rio de Janeiro, portanto, trata-se de uma informação extratextual, mais propriamente, contextual. Quintino Bocaiuva substituiu José de Alencar na direção do Diário, tornando a imprimi-lo em 25 março de 1860. O eminente republicano Saldanha Marinho assumiu o posto de principal redator. De acordo com Jean-Michel Massa, os outros redatores fixos eram Henrique César Muzzio e Machado de Assis (MASSA, 1971, p. 279-280). Teófilo Otoni, Charles Ribeyrolles, Pinheiro Guimarães Filho, Augusto Emílio Zaluar, Salvador de Mendonça e Francisco Ramos escreviam ocasionalmente no jornal.

O adolescente Machado de Assis já havia publicado versos no Diário, quando José de Alencar ainda era o redator-chefe (MAGALHÃES JÚNIOR, 2008, v.1, p. 34). Relevante é o fato de Quintino logo ter convidado Machado a tomar parte do novo projeto, como se lê em célebre passagem de "O velho Senado". Sabemos que apenas 23 dias depois da primeira edição sob a direção de Quintino, precisamente na quinta edição da reimpressão do periódico, em 29 de março, Machado escreveu uma apreciação da peça $M a \tilde{e}$, de José de Alencar, utilizando-se do pseudônimo “M. de A.”. Machado utilizará esta abreviatura para assinar outra crítica neste jornal (13 abr. 1860). Após longo interstício, a última crítica da série "Revista dramática" subscreverá o seu próprio nome (24 jul. 1861). Daí em diante, quando Machado passa a colunista fixo do Diário, ele assinará Gil (18 out. 1861 a 11 dez. 1861) e depois M. A. (16 dez. 1861 a 5 maio 1862) no semanário "Comentários da Semana", retornando com a série "Ao acaso" (5 jun. 1864 a 16 maio 1865).

Machado esteve com Quintino desde o início do projeto e é possível que lhe fossem atribuídas funções mais destacadas que as de revisor de provas e de editor de anúncios. Os primeiros quatro números do periódico, sob o comando de Quintino e Saldanha, possuem diversos artigos sem menção de autoria, muitos dos quais apenas repercutem notícias de outros 
diários. Há traduções requentadas, anúncios e transcrições do noticiário, sobretudo na parte comercial estabelecida nas duas últimas folhas do jornal.

Apesar do estado precário das primeiras edições de 1860, disponíveis na Hemeroteca Digital, vislumbra-se a assinatura de Saldanha Marinho, no primeiro editorial do jornal, na primeira coluna à esquerda. Espera-se que o texto do editorial seja responsabilidade do redator-chefe. Além deste, na primeira página figuram um breve noticiário e uma tradução, em folhetim, de La Quittance de minuit, de Paul Féval. Nesses primeiros números, os editoriais limitam-se a criticar as ações dos Ministros de Estado, especialmente o Ministro da Fazenda, no tocante às suas responsabilidades com os direitos constitucionais e com os demais poderes de Estado. Ambos estavam usurpados, de acordo com o Diário do Rio de Janeiro. Seja por precaução ou por outro motivo, as incriminações não possuem signatários.

O editorial resume as acusações contra os Ministros de Estado, antes de estampar a lei de 15 de outubro de 1827, que dispunha sobre os crimes e regulava o processo de responsabilidade de ministros e conselheiros de Estado. Porque o jornal estivesse reiniciando as suas atividades, ainda ajeitando o seu quadro de colaboradores, pode ser que o ensaio "A imprensa na atualidade" servisse para preencher anonimamente a lacuna da primeira página com algum assunto político, pois "era preciso vencer e aceitava-se de bom grado o anonimato" (MASSA, 1971, p. 281). Vale lembrar que as primeiras crônicas parlamentares escritas por Machado estão assinadas Gil. Neste emprego, "as horas vagas de Machado não eram muitas. Desde o início das atividades legislativas, fora despachado para o Senado do Império, onde iniciara uma atividade inteiramente nova - a de cronista parlamentar do Diário do Rio de Janeiro" (MAGALHÃES JÚNIOR, 2008, v. 1, p. 163).

O trabalho como correspondente do Diário no Senado do Império representava uma função central do projeto republicano de Quintino Bocaiuva e Saldanha Marinho, os quais não poderiam confiá-lo a um monarquista, menos ainda a um conservador. Em "O velho Senado", lemos uma descrição mais ou menos fidedigna dos fatos:

Nesse ano [1860] entrara eu para a imprensa. Uma noite, como saíssemos do Teatro Ginásio, Quintino Bocaiuva e eu fomos tomar chá. Bocaiuva era então uma gentil figura de rapaz, delgado, tez macia, fino bigode e olhos serenos. Já então tinha os gestos lentos de hoje, e um pouco daquele ar distant que Taine achou em Mérimée. Disseram coisa análoga de Challemel-Lacour, que alguém ultimamente definia como très républicain de conviction et très aristocrate de tempérament. $\mathrm{O}$ nosso 
Bocaiuva era só a segunda parte, mas já então liberal bastante para dar um republicano convicto. Ao chá, conversamos primeiramente de letras, e pouco depois de política, matéria introduzida por ele, o que me espantou bastante; não era usual nas nossas práticas. Nem é exato dizer que conversamos de política, eu antes respondia às perguntas que Bocaiuva me ia fazendo, como se quisesse conhecer as minhas opiniões. Provavelmente não as teria fixas nem determinadas; mas, quaisquer que fossem, creio que as exprimi na proporção e com a precisão apenas adequadas ao que ele me ia oferecer. De fato, separamo-nos com prazo dado para o dia seguinte, na loja de Paula Brito, que era na antiga Praça da Constituição, ao lado do Teatro São Pedro, a meio caminho das Ruas do Cano e dos Ciganos. Relevai esta nomenclatura morta; é vício de memória velha. Na manhã seguinte, achei ali Bocaiuva escrevendo um bilhete. Tratava-se do Diário do Rio de Janeiro, que ia reaparecer, sob a direção política de Saldanha Marinho. Vinha dar-me um lugar na redação com ele e Henrique César Muzzio. (ASSIS, 2015, v. 2, p. 580)

A memória é boa, mas o que não parece estar de todo correto é o suposto absenteísmo do jovem de vinte anos, camuflado pelo tom dubitativo - "provavelmente" - e dissimulado do autor desta narrativa, então considerado um não republicano e não conservador de sessenta anos. Segundo Massa, antes de se tornar o zeloso funcionário do Império, agradecido e fiel à família Real, e muito antes de transfigurar-se no misantropo com tédio a controvérsias (sobretudo as políticas), Machado não era, de forma alguma, absenteísta (MASSA, 1971, p. 292). Ademais, o Diário do Rio de Janeiro era um órgão das "trincheiras liberais" - denominação de Luiz Viana Filho (1965, p. 29) - pelo enfrentamento do recém-empossado gabinete conservador. Daí as ressalvas dos redatores contra os Ministros de Estado. No caso do artigo "A imprensa na atualidade", as críticas se dirigiam ao estado morno de coisas do próprio jornalismo brasileiro, que se submetia aos interesses do governo e dos poderosos e não sabia guardar "a integridade e independência da sua missão". O teste e o convite de Bocaiuva ocorreram, de acordo com a descrição do cronista, antes da reabertura do jornal. Portanto, é razoável imaginar que alguns textos das primeiras edições, não assinados ou com pseudônimos diversos das variantes "M. A." e "M. de A.", saíssem da pena de Machado.

A segunda razão para a atribuição de autoria deve-se ao estilo de escrita do jovem Machado de Assis, primeiro no que diz respeito ao modo de publicação, tendo em consideração o caráter seriado dos textos ensaísticos: "Os imortais" divide-se em duas partes. Do mesmo modo divide-se "O 
passado, o presente e o futuro da literatura". "Ideias vagas" contém três textos, assim como "Os cegos". As "Aquarelas" foram publicadas em quatro partes. E as "Ideias sobre o teatro" foram publicadas em três edições de $O$ Espelho e arrematadas em A Marmota. De todos os ensaios deste período, apenas "A reforma pelo jornal" foi publicada de uma só vez, mas há boas razões para considerá-la uma continuação de "O jornal e o livro", publicado em duas partes. Pode ser que a composição seriada fosse necessária devido à lógica jornalística de oferecer notícias e informações curtas ou mesmo de favorecer o marketing dos autores sobre os leitores, obrigando-os a adquirir as próximas edições do jornal para completarem a narrativa. No longo prazo, pode-se até estabelecer elos entre ensaios como "O ideal do crítico" (1865) e "Notícia da atual literatura brasileira - Instinto de nacionalidade" (1873) e "A nova geração" (1879).

Seja como for, aqui estamos diante de uma série inusitada para os padrões do jovem Machado, já que os títulos possuem uma relação circunstancial: eles resumem as teses, como o título "O passado, o presente e o futuro da literatura", mais do que exprimem um sentimento genérico sobre o assunto tratado, como "Aquarelas" e "Ideias vagas".

O primeiro artigo da série, "O jornal e o livro", compara a situação do jornal e do livro com base em uma tese progressista da história, retomada no artigo seguinte. Esta retomada é manifesta pelo autor: "A imprensa, que encarnava a ideia no livro, expedi eu em outra parte" (ASSIS, 2015, v. 3, p. 1018), isto é, em "O jornal e o livro", porém, a conclusão otimista e abrupta de "A reforma pelo jornal" teria de ser revista ou, pelo menos, emendada1. Ela não é uma consequência dos argumentos relacionados à evolução da comunicação humana, mas apenas uma expectativa de que o jornal se tornará, entre nós, a base do progresso social e econômico. "A atualidade da imprensa" reconstrói o argumento e arremata a série, como veremos adiante, invertendo a expectativa otimista em prospecto desolador.

Alguns vícios de linguagem ou reiterações são encontrados nos três textos, como o uso constante do advérbio "decerto", a metáfora da "locomotiva intelectual" para designar o jornal, presente na primeira e na segunda partes do primeiro artigo e recuperada em "A atualidade da imprensa". Além disso, a qualificação do livro como uma "catedral portátil”,

${ }^{1} \mathrm{Na}$ quarta parte da série Aquarelas, publicada uma semana depois do artigo "A reforma pelo jornal", Machado faz uma autorreferência suposta ao texto "O jornal e o livro": "disse eu em outra parte, e debaixo de outro pseudônimo, o folhetim nasceu do jornal" (ASSIS, 2015, v. 3, p. 1006). Em artigo recente, publicado na Machado de Assis em Linha, Fernando Borsato (2019) contesta a referência, argumentando que Machado estava mencionado o primeiro capítulo de "A lanterna de Diógenes" (texto inédito), publicado no Correio da Tarde, em 22 de outubro de 1858. 
no artigo de 27 de março de 1860, ganha sentido se lembrarmos do que está escrito, no primeiro, sobre a catedral na Idade Média, o meio cultural de propagação de ideias da época. As afinidades no vocabulário poético são cruciais para Magalhães Júnior atribuir uma poesia a Machado, em desfavor dos argumentos reticentes de Galante de Sousa, ao fim coligidas pelas Obras completas com o título "A madame de Lagrange" (MAGALHÃES JÚNIOR, 2008, v. 1, p. 131). Na interseção entre a poesia e a tradução, o estudo recente de Diego Flores identifica traços estilísticos ou marcas autorais para atribuição de quatro traduções a Machado de Assis, quais sejam, "O rei dos ôlmos (Balada de Goethe)", "Lua da estiva noite", "O coração" e "Inocência", embora tivessem sido consignadas por Magalhães Júnior (FLORES, 2019, p. $207,215,330$ e 336$)$.

A última razão é, a meu ver, a mais significativa, pois toma a própria obra literária - com os desvios próprios de uma posição teórica de todo não estabelecida - como termo de comparação. Teses comuns podem ser reexaminadas e colocadas a novos testes, bem como ser evidenciadas as modificações das perspectivas presentes em textos anteriores. Há que se pressupor, neste caso, a hipótese de que os textos pertencem ao mesmo autor.

Em “O jornal e o livro", Machado toma por verdadeiro o princípio filosófico de que o espírito humano tende à perfeição. Trata-se da tese de Eugène Pelletan defendida em Le Monde marche (1857), livro que se tornara, nas palavras de Machado, “o Evangelho de uma religião”. Pelletan tentava conciliar o programa desenvolvimentista do Século das Luzes, em pleno vigor nas economias mais avançadas, com os dogmas da tradição cristã. Como se a história da humanidade acompanhasse uma lei divina, a saber, a lei do progresso contínuo:

Cada movimento do ser operado na criação, pela lei da criação, tem seu polo, seu fim. Este polo, este fim é Deus, é o infinito. A vida universal [...] tende constantemente a Deus, em virtude de sua inspiração divina, e constantemente a ele remonta pela infatigável espiral e inesgotável circunvolução do progresso. [...] Quem diz progresso diz movimento de Deus. (PELLETAN, 1866, p. 182)

A leitura desta Bíblia e a descoberta de um Deus do progresso devem ter ocorrido no final de 1858, quando o poeta-profeta passou a ter a missão gloriosa, cuja profissão de fé anunciava-se em "Esperança" e "A missão do poeta". No mesmo ano, Machado escreveu a poesia "O progresso", com a seguinte dedicatória: "Hino da mocidade/ Ao Sr. E. Pelletan/ E pur si 
muove!", isto é, "move-se, no entanto" - resposta irônica atribuída a Galileu durante processo no tribunal do Santo Ofício, por sua defesa herege do heliocentrismo. A geração de Machado se moveu nesse processo de grandes transformações culturais, orbitando ao redor do pensamento liberal e do espírito progressista de sua época: "Fala mais alto, irmãos, a ardente humanidade! / Marchando a realizar uma missão moral; / E pregando uma lei, uma eterna verdade, / Do progresso a subir a mágica espiral." (ASSIS, 2015, v. 3, p. 714).

A tese de que o espírito humano tende à perfectibilidade é novamente defendida no ensaio "O jornal e o livro". A diferença entre escrever poesia e escrever um artigo de jornal não é apenas formal: a poesia e a política são "duas faces bem distintas da sociedade civilizada". A premissa que restava escondida, descoberta com Pelletan, era que a missão do jornalista coincidia com a última volta da roda do progresso. Em comparação ao livro, o jornal era mais adequado à regeneração do povo. A tarefa do jornal era determinada pelas novas leis de mercado, segundo o princípio da livre iniciativa, da liberdade de troca e da balança invisível entre oferta e demanda:

[...] o desenvolvimento do crédito quer o desenvolvimento do jornalismo, porque o jornalismo não é senão um grande banco intelectual, grande monetização da ideia, como diz um escritor moderno. (ASSIS, 2015, v. 3, p. 995)

É provável que a referência seja a John Law (1671-1729), economista escocês e teórico do sistema bancário moderno. Alguns meses depois, em uma polêmica contra o Ministro da Fazenda, Machado citará Law diretamente. Então militante de oposição, Machado de Assis manifesta seu engajamento na crônica "A odisseia econômica do Sr. Ministro da Fazenda", de junho de 1859. Embora não dispusesse de argumentos técnicos, ele já dominava a retórica da zombaria ad hominem, mobilizando-a contra um projeto econômico do Ministro da Fazenda. Sales Torres Homem havia sido um publicista do liberalismo, tendo criticado duramente a política econômica do jovem Pedro II. Convertido ao conservadorismo, o então ministro adotou medidas de contenção do crédito e dos juros, ferindo a primeira lei da sociabilidade, qual seja, da "necessidade de troca", nos termos de John Law, ou a lei da "necessidade pública", nos termos do Machadinho.

A originalidade desse artigo consiste em testar a hipótese ao caso local. Ele compõe o desenvolvimento de uma tese, juntamente com artigo "A odisseia econômica do Sr. Ministro da Fazenda" (jun. 1859), a série 
“Aquarelas" (set. e out. 1859) e "A reforma pelo jornal" (out. 1859). A questão de fundo era saber se nosso espírito estava no mesmo compasso do espírito europeu, melhor dissera se estávamos em condições de compartilhar e usufruir dos resultados da civilização. De início, era preciso dar resposta a outra questão: seria o jornal a manifestação do espírito livre e republicano, superior ao livro?

Tudo se regenera: tudo toma uma nova face. O jornal é um sintoma, um exemplo desta regeneração. A humanidade, como o vulcão, rebenta uma nova cratera quando mais fogo lhe ferve no centro. A literatura tinha acaso nos moldes conhecidos em que preenchesse o fim do pensamento humano? Não; nenhum era vasto como o jornal, nenhum liberal, nenhum democrático, como ele. Foi a nova cratera do vulcão. (ASSIS, 2015, v. 3, p. 991-992)

$\mathrm{O}$ jornal parecia mais perfeito às exigências do pensamento contemporâneo. Ele era o meio adequado de propagar ideias ao público em geral, já que propiciava a tomada de consciência das massas populares em relação a sua importância no firmamento do pacto social. Ele refletia as ideias do cotidiano popular e promovia a discussão, o "movimento" dialético em direção à perfectibilidade. E mais: o jornalismo era imprescindível para formação de uma república das letras, não mais pautada pelo favor nem pelo mecenato de salão, mas pela liberdade de expressão e pelo talento individual.

O jornal representava a nova revolução "do espírito humano sobre as fórmulas existentes do mundo social, do mundo literário e do mundo econômico" (ASSIS, 2015, v. 3, p. 994). Esse espírito subversivo conservou-se n'O Espelho, sobretudo em "A reforma pelo jornal". O título é mais incisivo que o anterior. A "reforma" anunciada refere-se à democratização do pensamento. A palavra, o "verbo", manifestou-se historicamente de maneira monocrática, seja no púlpito ou nos livros. O jornal abria o espaço democrático para discussões. A liberdade de expressão, essa pequena liberdade de que fala Kant, poderia promover consensos para uma organização social menos desigual. Do ponto de vista econômico, a tese ainda era a mesma: o jornal seria a expressão de um grande banco intelectual, cujo crédito eram as ideias e cujo valor determinava-se pela concorrência entre os jornalistas. Segundo o biógrafo Jean-Michel Massa:

[...] tratava-se de uma reivindicação, que explodiu no país ainda bastante paternalista que era o Brasil. Por essa profissão de fé democrática, Machado de Assis confirmava sua solidariedade às classes 
populares. Atacou aqueles que se opunham à elevação social dessas classes. Analisou os receios dos aristocratas diante dos movimentos populares, diante da ascensão das inteligências proletárias. A imprensa, que divulgava a "palavra", agente e elemento de cultura, dava aos humildes um verdadeiro surto de progresso. (MASSA, 1971, p. 265)

Este segundo artigo da série expressa uma ideologia antiaristocrata pautada pelos princípios da discussão pública e da inclusão das "inteligências proletárias". A esperança, positiva para o país, é de que o destino estava traçado e o iluminismo jornalístico havia de vencer as trevas da aristocracia. $\mathrm{O}$ último entrave era o patrimonialismo presente nas estruturas de poder, e também na imprensa, que sufocava os talentos novos, sem cooptação e adaptados ao livre mercado das ideias.

Em "A imprensa na atualidade" os argumentos são concatenados de maneira semelhante, como se o autor estivesse revisitando uma perspectiva teórica pessoal. Nos primeiros parágrafos, o autor recupera as metáforas da "locomotiva intelectual" e do "espírito da civilização" em direção ao progresso e à perfeição. Repete-se, ainda, a ideia de que o jornal é democrático, patriótico, "o desmembramento do livro, a crônica atual, a tribuna contemporânea". O que se desenrola, na sequência do texto, é uma resposta menos otimista e mais realista em relação aos entraves, no caso brasileiro, da promoção da civilização e do desenvolvimento social promovidos pelo jornal. Em primeiro lugar porque, à exceção possível do trabalho de Evaristo da Veiga, o jornalismo não era realidade no país. Havia um descompasso entre o que essa prática deveria e poderia ser, prescrita nos artigos anteriores, e o que ela de fato era, diga-se, da perspectiva de um jornal oposicionista. Diferente do que pode parecer quando lemos a confissão de Machado em "O velho Senado", quando ele diz que Quintino buscava meios de saber se suas ideias políticas estavam de acordo, levando Machado a disfarçar algum republicanismo para ganhar o emprego, desde "O jornal e o livro" se fazia a apologia ao republicanismo, ou seja, Machado tinha todas as credenciais - contrárias ao governo - para ser recrutado por Quintino. Talvez ele e Salvador tenham ponderado não expor o jovem escritor a uma estreia bombástica, já que o artigo do Diário do Rio de Janeiro é muito mais incisivo que os anteriores, ao criticar o sistema eleitoral, o sistema de governo, a política econômica, o clero, a polícia e a magistratura, além, é claro, do próprio modo de operação do jornalismo brasileiro. Essa reticência pode explicar o uso do pseudônimo Gil nos primeiros "Comentários da Semana". Seja como for, as razões apresentadas em 
conjunto, de ordem biográfica, estilística e comparativa, apresentam critérios editoriais de seleção utilizados por bibliógrafos em outras circunstâncias, indicando que "A imprensa na atualidade" possa ser a primeira contribuição de Machado para o Diário.

\section{Conclusão}

Caso não houvesse escrito o ensaio que ora atribui-se a Machado de Assis, deveríamos considerar a sua perspectiva da juventude sobre o jornal como ingênua, dado o excesso de entusiasmo aos valores do sistema econômico liberal. Tanto mais porque o próprio trabalho do jornalista e do artista, ao contrário do prognóstico realizado nos primeiros artigos, se transformava em mercadoria como outra qualquer, sem maior deferência e concessão ao talento do indivíduo. Por aqui o liberalismo teórico esbarrava nas determinações do favor e da clientela. Esse é o avanço do autor de "A imprensa na atualidade" em relação aos ensaios anteriores. É como se ele começasse a desconfiar de que o outro prato da balança comercial, a demanda leitora, era pequena demais para compor um verdadeiro mercado. A crer na atribuição de autoria, este é um artigo chave para compreender o vai e vem ideológico do jovem Machado, de republicano a monarquista, de liberal a crítico do capitalismo, de materialista a espiritualista eclético, com rasgos de ceticismo em qualquer época. O ensaio, a tentativa e o erro providenciaram algum senso crítico e a precaução de não se concluir verdades enquanto as premissas forem falsas. Por sorte ou por virtude, aquele entusiasmo excessivo pelo capital, presentes em "O jornal e o livro" e “A reforma pelo jornal” não ultrapassou as fronteiras da década de 1850.

Até onde se apurou, o artigo "A imprensa na atualidade" não está relacionado na bibliografia de Galante de Sousa, nem nos dispersos recolhidos por Massa e Magalhães Júnior, tampouco é mencionado nas biografias consultadas de Miguel Pereira, Massa, Viana Filho e Magalhães Júnior. Para dar o crédito a quem mereça, Marco Cicero Cavallini aponta a semelhança temática entre o artigo de março de 1860 e os ensaios anteriores de Machado de Assis, considerando-o, contudo, como se fosse o editorial daquela edição, quando o verdadeiro editorial antecede o texto ora atribuído a Machado (CAVALLiNI, 1999, p. 42-43 e CAVALLINI, 2005, p. 29-30). Resta lamentar que a transcrição do artigo não pôde ser realizada sem que alguns trechos fossem suprimidos - indicados entre colchetes, na transcrição 
-, por causa da má condição em que se encontra o arquivo digitalizado no acervo da Hemeroteca Digital da Fundação Biblioteca Nacional.

A segurança da atribuição deste ensaio a Machado de Assis é diminuída pelo fato de não termos encontrado um dado exterior ao texto e que aponte, definitivamente, a autoria machadiana, seja pela comparação de caligrafias, como a atribuição da poesia "O casamento do Diabo", em que o original fora preservado, publicado por Múcio Leão e recolhido pela Bibliografia de Machado de Assis, seja por desvelamento de pseudônimos por contemporâneos como Joaquim Serra ou pelos trabalhos de Teixeira Melo e Inocêncio Silva, que consignam, por exemplo, o pseudônimo Gil, seja por indicações do próprio autor ao se referir a textos e contextos pregressos. Um contra um, estes critérios de atribuição são mais decisivos do que aqueles que apontamos - os indícios biográficos, os traços estilísticos e a congruência temática -, embora estes, em conjunto, fortaleçam a probabilidade da autoria.

\section{ANEXO}

TRANSCRIÇÃO DE "A IMPRENSA NA ATUALIDADE"

Diário do Rio de Janeiro, n. 3, Rio de Janeiro, 27 mar. 1860, f. 1.

Quando o espírito da civilização ganhou este grande auxiliar da imprensa, ideia de uma época absolutamente venturosa para o gênero humano deixou a dubiedade de uma hipótese para tomar a consistência de uma verdade.

Com essa locomotiva intelectual não haviam distâncias possíveis; a atividade humana, encontrando uma moeda mais sólida para cunho, fazia ampliar os seus horizontes e multiplicar os seus elementos.

Com estas proporções, a imprensa, entre outras reformas, atacava muito de perto o princípio da autoridade; e foi, conhecendo essas tendências perigosas, que o poder tratou de atenuar a violência de seus primeiros voos; esforço profícuo ao princípio que o espírito da civilização devia [relaxar] mais tarde.

Temia a imprensa, como as aves da noite temem a luz; os cultos sombrios da antiguidade cairiam cobertos de ridículo, se a imprensa fosse um fato [primitivo] [...]

A razão [deste fenômeno] está na própria essência do invento. Sendo um meio mais fácil e mais numeroso de reprodução, punha ao alcance de todos uma arma para discussão, uma chave para exame. 
Quando a ideia tem muitos poros para filtrar, vem mais abundante, mais [fremente] e mais disseminada; ora, a ideia é luz e desde que há mais luz, por um princípio de física, há menos escuridade; desde que há mais exame, por um axioma filosófico, há menos aceitação de doutrinas caducas, menos fé de princípios velhos.

Mas a imprensa tem [dado] moldes muito distintos: o livro e o jornal [O livro] que é a arca, a conservação do [passado], a catedral portátil, o sacrário dos [evos]; o jornal, que é o desmembramento do livro, a crônica atual, a tribuna contemporânea, - [pão] barato ao alcance de todas as fortunas.

São diferentes e importantes os papeis destas duas formas tão distintas da imprensa. Constituem ambas as duas faces da grande moeda dos povos.

Duas palavras, porém, sobre o jornal.

Cremos que ninguém será de uma candidez tão primitiva, que acredite de boa-fé que o jornalismo é, entre nós, um fato. Não há mesmo vontade patriótica que justifique uma asserção semelhante.

Houve talvez tentativas, auroras boreais, com grandes intervalos, arremedos felizes; mas trabalho completo, igual [e] inteiriço, nunca passou de uma utopia.

Houve talvez alguma semente fecunda no circo das nossas lutas passadas; houve talvez exemplos tocantes nos dias de glória dessa probidade política chamada Evaristo da Veiga; mas a erva cresceu no caminho aberto, e agora está impraticável e agreste.

E a culpa não foi dos gregos, mas dos troianos, que não souberam guardar a integridade e independência da sua missão; que abriram as portas ao cavalo engenhoso dos sitiantes, e que, quando menos pensaram, acharam-se vencidos e aprisionados.

Foi deles a culpa. Custava pouco um protesto, um esforço, mas eram homens, e caíram no erro; pobre Aquiles que não puderam resistir às delícias da Cápua política.

Quando um dia foi forçoso às ambições secretas uma fusão de princípios, um abraço de opiniões; quando conveio abater a muralha que extremava a ideia liberal da ideia conservadora, fechou-se à chave a tuba da opinião pública, e assinaram, sem protesto, o tratado de paz.

O jornalismo foi, pois, adulterado; fugiram da linha prescrita, e constituíram essa forma soberana da imprensa em poste público e ridículo, domínio das ambições ilegítimas e dos ódios privados.

Entretanto, se o jornalismo estivesse no seu verdadeiro caminho, tinha 
na atualidade um grande papel a representar.

Quem lançar um simples olhar sobre o estado atual da nossa sociedade convence-se de que esse caminho próspero que parece levar a caravela pública, não passa de um equívoco dos míopes que vão dormindo descansadamente em um mar de idealidades.

Com efeito, chegamos a um período de corrupção e de desfalecimento mais real do que parece, e menos fácil de crer em tão poucos anos de vida. É doloroso, mas é verdade. [Se examinarmos...] talvez poucas [coisas] no corpo social que não tenham sido vítimas desse princípio de corrupção.

Houve um tempo em que as opiniões, deslumbradas pelas belezas dos altos cargos, começaram a perder a consciência dos princípios e a dignidade do dever. As bandeiras políticas desmaiaram a olhos vistos, os princípios recuaram para dar lugar aos nomes, e o poder era olhado como uma bela prerrogativa para nulificar na individualidade elevada a ação de certos artigos do nosso estatuto criminal.

Foi de semelhante estado de coisas que se caminhou para a tremenda utopia da conciliação.

Desde esse tempo as consequências morreram deveras; não há vontade dedicada, nem espírito patriótico. Os sistemas eleitorais não puderam acabar com as fraudes que levam ao parlamento os potentados sem mérito.

Nessas ridículas comédias representadas de quatro em quatro anos, aboliu-se a expressão nacional, a liberdade do voto, para dar lugar às opressões mesquinhas e às vinganças tolas, com que muita parvoíce se constitui eleito do povo.

É esta e não outra a tradução que se tem dado ao princípio constitucional, à verdade política do nosso sistema de governo.

O clero não pôde também escapar à ação fatal da lepra pública. Sacerdotes de um dogma tão santo como a religião social, dormiram também como os outros, e os acompanharam na onda que os levou.

Temos a parte financeira do país.

O descuido dos homens, por cujas mãos têm passado as rédeas do poder, levaram as forças econômicas do país a tal situação de desfalecimento, que um dia acordarão eles assustados deveras.

Cessado o tráfico africano, a escravidão caminhou para o aniquilamento, de sorte que um dia compreendeu-se a necessidade de colonizar estrangeiros para substituir os braços que se iam acabando. Ensaiaram, mas como! ensaios fúteis, em que importaram, entre outras, uma 
raça decrépita e fraca, sem nenhumas proporções para os fins precisos.

Este estado de coisas reduziu a lavoura a um quebrantamento supremo. As exportações são hoje tênues, e prometem um futuro pouco risonho ao país.

Por toda a parte se reclamam reformas; a guarda cívica e a magistratura postas aos caprichos altos; uma polícia com ares de barão feudal da Idade Média, esbulhando os cidadãos do direito de liberdade, para satisfazer às vezes paixões ou vontades secretas; a instrução coxa, as prerrogativas vendidas, a dignidade nacional comprometida, são um fundo pouco luminoso do quadro atual da nossa sociedade.

Ora, se o jornalismo tivesse compreendido a sua posição, e se não a houvesse deixado para ir sentar-se à mesa dos Lúculos políticos; se a imprensa do nosso país, em vez de abrir a porta às rixas privadas, aos interesses individuais, conservasse a pena como utilidade pública; em vez de estabelecer o princípio do ganho, limpasse a arena da discussão para o combate sério, leal, útil: o jornalismo entre nós seria uma verdade e uma prerrogativa, e teria na atualidade um importante papel.

Esse papel tinha dois lados a encarar; ou tomar a iniciativa no sentido de melhorar a situação; ou, se da geração atual nada [houver] a esperar, tratar de [...]. Por qualquer destes caminhos a missão era sublime e os resultados altamente felizes para o país. Mesmo quando o êxito fosse duvidoso, não lhe bastava cair com a bandeira, cair com a cruz, com os aplausos da consciência?

Esta missão, se a compreendesse bem, seria o seu maior documento para o futuro, o seu maior protesto em nome da parte moralizada do país. As maldições dos Baltazares modernos não cobririam o eco das bênçãos e das palmas.

Cair assim não é uma derrota, é um triunfo.

\section{Referências}

ASSIS, Joaquim Maria Machado de. Obra completa. 4 vols. Organização editorial Aluizio Leite, Ana Lima Cecílio, Heloisa Jahn. São Paulo: Nova Aguilar, 2015.

BORSATO, Fernando. Ponto de interrogação: pseudônimo desconhecido e texto inédito de Machado de Assis. Machado de Assis em Linha, São Paulo, v. 12, n. 28, p. 55-72, dez. 2019. Disponível em <http://machadodeassis.fflch.usp.br/> Acesso em 7 fev. 2020. 
CAVAllini, Marco Cícero. O Diário de Machado: a política do Segundo Reinado sob a pena de um jovem cronista liberal. 1999. 158 f. Dissertação (Mestrado) Curso de História, Departamento de História do Instituto de Filosofia e Ciências Humanas, Universidade Estadual de Campinas, Campinas, 1999.

. Letras políticas: a crítica social do Segundo Reinado na ficção de Machado de Assis. 2005. 175 f. Tese (Doutorado) - Curso de História, Departamento de História do Instituto de Filosofia e Ciências Humanas, Universidade Estadual de Campinas, Campinas, 2005.

FLORES, Diogo do Nascimento Rodrigues. Machado de Assis, poeta-tradutor. 2019. 468 f. Tese (Doutorado) - Curso de Letras, Centro de Ciências Humanas e Naturais, Universidade Federal do Espírito Santo, Vitória, 2019.

Diário do Rio de Janeiro [RJ]. n. 3, 27 mar. 1860, f. 1. Typografia do Diario. Disponível em: <http://memoria.bn.br/DocReader/094170_02/12708>. Acesso em 21 jan. 2019.

MAGALHÃES JÚNIOR, Raimundo. Vida e obra de Machado de Assis. 2. ed. Rio de Janeiro: Record, 2008.

MASSA, Jean-Michel. A juventude de Machado de Assis. Rio de Janeiro: Civilização Brasileira, 1971.

PELLETAN, Eugène. Cartas a Lamartine: o mundo marcha. Traduzido por S.P. Nolasco. São Luís: Typ. B. de Mattos, 1866. Disponível em: $<$ https://goo.gl/O1XhLb>. Acesso em 1 nov. 2019.

SOUSA, José Galante de. Bibliografia de Machado de Assis. Rio de Janeiro: MECInstituto Nacional do Livro, 1955.

VIANA FILHO, Luiz. A vida de Machado de Assis. São Paulo: Livraria Martins Editora, 1965.

ALEX LARA MARTINS é doutor em Filosofia pela Universidade Federal de Minas Gerais (UFMG), com tese sobre Machado de Assis. Fez a graduação em Filosofia na UFMG, com formação complementar aberta e ênfase em Letras, e mestrado em Filosofia pela mesma Universidade. É professor do Instituto Federal do Norte de Minas Gerais desde 2013. Como pesquisador, atua principalmente nos seguintes temas: Literatura e Filosofia, Ceticismo, Machado de Assis, Teoria da ficção, Filosofia no Brasil, Filosofia do Ensino Médio. É autor do livro Machado de Assis: o filósofo brasileiro (Porto Alegre: Editora Fi, 2017).

(iD https:// orcid.org/0000-0002-0579-4933. E-mail: alex.lara@ifnmg.edu.br

Recebido: 14.11.2019

Aprovado: 10.01.2020 